\title{
Imagens da nação, do progresso e da tecnologia: a Exposição Universal de Filadélfia de 1876
}

\begin{abstract}
"L'image est universellement présente au XIXe siècle. Objet de piété ou photo de famille, elle loge au coeur de la vie privée stafue gigantesque, Marie ou Liberté, elle règne sur la ville dont elle commande le sens; entre les deux, elle gouverne l'imprimé par la vignette, la caricature, organise l'espace de la pensée et fixe dans sa fulgurance la plus haute ambition du poète. Quel secteur lui échappe lorsque la civilisation, changée en immense machine à voir ef à faire voir, s'ordonne toute entière autour du spectacle lors des expositions dont le siècle a le secret".

Stéphane Michaud (1990).
\end{abstract}

Múltipla, enigmática e sedutora, veículo de comunicação e de reflexão, processo ao mesmo tempo de revelação e ocultação, "a imagem está no coração de uma rede de sentidos, que desvela os valores íntimos de uma época" (Michaud 1990: 10).

Todas as sociedades, ao longo da sua história, têm elaborado um sistema de idéias e imagens de representação coletiva, através do qual se atribuem uma identidade, pautam valores, normatizam condutas. Neste sentido, as imagens fariam parte do que se convencionaria chamar imaginário social, este vasto campo de representação do real que, se com ele não se confunde, seria, ao mesmo tempo, o seu "outro lado".

As representações coletivas, compostas de imagens e discursos, não são, necessariamente, o reflexo das condições concretas da existência, mas com elas guardam uma aproximação e, por sua vez, são geradoras de práticas sociais. O imaginário social é, pois, representação, ou seja, a tradução mental e visual de uma realidade exterior percebida. Mas, ao lado do fio-terra, que o 
liga à concretitude do real que $\circ$ inspira, o imaginário comporta uma dimensão de ilusão do espírito, de intenção deliberada e distorção que obedece a fins desejados e a que se pode dar o nome de ideologia. Por outro lado, o imaginário comporta uma dimensão criadora, utópica, de sonho, desejo e vir-a-ser, fantástica ou não, manifestadora de um inconsciente coletivo.

Na composição do imaginário enquanto representação, estabelece-se uma distinção entre discursos e imagens, ou entre palavras e "coisas", no sentido figurativo. Todavia, sendo ambas representações, a imagem é o veículo visual de uma idéia, suporłando uma mensagem discursiva. Por sua vez, o discurso evoca uma imagem mental que reporta ao real. Como refere Rebérioux (1990: 51, "a significação de um texto não se deduz exclusivamente das palavras que nele são asseguradas, mas também das imagens que o acompanham".

Ser e não ser, isto e aquilo, interpenetração das instâncias: são índices reveladores do fascínio e do relativismo que marcam os modernos estudos da história cultural:

Mas voltemos à imagem.

Assim como houve uma tendência a fazer do imaginário a matriz do erro e da falsidade, numa linha de racionalismo que vai de Descartes a Comte, também a imagem, no pensamento de Sartre, aparece como que desvalorizada diante do conceito (cf. Durand 1984: 24). Como ser menor, ou reflexo empobrecido real, a imagem seria, pois, um decalque, um falso dublê de algo, uma fatal imitação

Já Louis Marin (1992: 10), ao analisar os poderes da imagem, considera que a sua força vem do seu ser, ou da característica de ser representação de algo.

Assim, a imagem é "a enunciação poderosa de uma ausência", ou a "re-presentação", no sentido de apresentar de novo ou por-se no lugar de. Há um ausente no tempo e no espaço, que se presentifica pela imagem, da mesma forma que se realiza uma auto-representação, revelando-se um sentido (cf. Marin: 1992). Tal processo implica uma modificação perceptiva do real, induzindo o acesso a um sentido não lisível de forma literal (cf. Durand 1988).

Há, pois, com a imagem, um poder de evocação e de revelação de um significado. Mas, enquanto representação, a imagem é simbólica por natureza: uma coisa ausente é representada por outra, que visa à reconstrução instauradora de um ser. Através de sua parte visível - o símbolo ou significante -, a imagem presentifica o distante, mas reporta-se a um sentido. Nesta medida, a imagem é um signo, dimensão invisivel, portadora de um significado (cf. Durand 1988).

Desta forma, através das imagens, reconstitui-se o real através de um universo paralelo de sinais (cf. Dubois 1988).

As imagens são simbólicas e exprimem uma metaforização do social. O objeto a ser representado é remetido a um sistema de valores subjacentes, cuja significância extrapola os limites do representado.

Como refere Castoriadis (1992), tudo no mundo social se apresenta entrelaçado com o simbólico, pois o que chamamos "realidade" necessita da rede de representações constituídas e atribuídas para "existir". 
Neste sentido, o mundo das imagens fornece uma das chaves para o entendimento da história, no qual se busca atingir o "real" pelo estudo das suas representações.

Nosso fin-de-siècle é particularmente dominado pela imagem, portadora de múltiplos sentidos e significados, de uma tal forma que suas dimensões alegóricas e metafóricas, veiculadas pela mídia, parecem se constituir numa característica de nossa contemporaneidade. Entretanto, o século XIX foi, por excelência, uma época dominada pela imagem, num entrecruzamento de significações trazidas à baila pela sociedade burguesa. $O$ fenômeno industrial da multiplicação de imagens, possibilitado pelos avanços da tecnologia, não escapou à arguta visão de Benjamin (1986), na contraposição analítica feita entre a perda da aura da obra de arte e o seu valor de exposição, dado pela sua reproductibilidade técnica. Com a fotografia, o cinema, o cartaz, a proliferação dos jornais, das caricaturas e charges, o século XIX realizou como que uma hipertrofia do olhar, pela vulgarização das imagens (cf. Hamon 1992).

Historicizadas, as imagens pertencem a uma determinada época, e sua legibilidade nos daria uma chave de entrada para o passado. Parece ter sido esta a preocupação de Benjamin: a de decompor uma época em imagens, com o que pretendeu fazer uma arqueologia do universo cultural do século XIX.

Para Benjamin (1985), esta hermenêutica do passado, que permitisse - resgate do sentido simbólico e latente das imagens, seria dada pela conjunção sincrônica de passado e presente, a que chamou de dialética da paralisia, quando as imagens de uma época tornam-se legíveis no presente. No raciocínio de Benjamin, seria o pensamento dialético o instrumental para o historiador penetrar nesta conjunção privilegiada, lendo, numa outra época, o seu presente. A categoria central de análise que permitiria esta conjunção e legibilidade seria a do fetichismo da mercadoria, presente na sociedade capitalista. Ou seja, a propriedade de transfiguração das coisas de mascarar a essência dos processos e sentidos, revelando uma aparência alegórica e fetichista do real.

Nossa proposta é, pois, a de analisar a realidade através das suas representações (cf. Chartier 1987). Mas as imagens, como representação de um ausente, enunciação de um outro, precisam ser estudadas na sua coisificação. Falar em século XIX, atravessado pelas imagens, é deparar-se com fotografias, caricaturas, charges, pinturas.

Por um lado, são imagens portadoras de mensagens discursivas e, por outro, são matrizes de práticas sociais, e é pelo seu cruzamento - da prática com as representações - que se tornará possível desvendá-las.

Já dizia Louis Marin (1992): "a única forma de reconhecer a força da imagem será reconhecer os seus efeitos, lendo nos sinais do seu exercício sobre os corpos que otham e os interpretando nos textos em que estes sinais estão escritos, nos discursos que os registram, contam, transmitem e amplificam, até captar qualquer coisa da torça que os produziu".

Há, portanto, toda uma expectativa de resposta dos espectadores às imagens, toda uma recepção do leitor às mensagens aparentes e explícitas do enunciado exposto. 
Quer parecer que, no século XIX, as exposições universais foram um palco privilegiado de teatralização destes processos, veiculando imagens da nação, do progresso e da tecnologia, portadoras de um sentido implícito de transfiguração do real.

A rigor, as imagens do mundo industrial acham-se a serviço de uma hermenêutica do real, que comporta tanto os dados da realidade objetiva convulsionados pela transformação capitalista do mundo, quanto o ideário burguês, incorporando ainda a dimensão utópica da época.

As exposições universais que se realizaram na segunda metade do século XIX tiveram um caráter de feira de mercadorias, "lições de coisas", mostruário de novidades, locus de realização do lucro capitalista.

Endossa-se, contudo, a posição da historiadora Madeleine Rebérioux (1979: 3), quando se diz convencida a por, temporariamente, "entre parênteses", as dimensões explicitamente econômicas da pesquisa, para avançar no instigante caminho das análises que privilegiam as facetas culturais: "a exposição é, com efeito, criadora, no mais alto ponto, das representações mentais e do imaginário coletivo".

Empreendendo este caminho, Walter Benjamin já afirmara que as exposições universais eram lugares de peregrinação da mercadoria como fetiche. Num mundo regido pelo valor da troca, pode-se dizer que, através das exposições universais, manifestava-se uma certa forma de representação do real, que vulgarizava o ideário burguês, ao mesmo tempo que cristalizava os sonhos da época.

Neste sentido, as exposições universais foram arautos da nação, do progresso e da tecnologia, difundindo imagens fantasmagóricas de desejo coletivo.

A nação é, em si, uma comunidade política ilusória, baseada numa identidade referencial, que joga com as dimensões do espaço e tempo. A nação se apoia num território e na construção de um passado comum, além de lidar com os fatos da língua, credo e etnia, que visam construir um elo de ligação entre os povos.

Enquanto representação, a idéia da nação é, em si, agregadora dos indivíduos e diluidora das diferenças sociais. A nação é formada pelo povo, e este conceito enfatiza a unidade na diversidade. É sintomático o banimento da noção de classe e a acentuação das diferenças regionais, culturais e étnicas em detrimento das desigualdades sociais. Por outro lado, o imaginário sobre a nação trabalha com símbolos, imagens estereotipadas de identificação nacional: bandeira, tipo característico do "povo", cores, trajes, alegorias. Palavras e imagens se confundem em articulação simbólica e estabelecem o contraponto identidade/alteridade: "nós" e os "outros".

Naturalmente, esta construção imaginária do social expressa relações de poder. Invocando Bourdieu (1982), poder-se-ia dizer que tais construções expressariam uma forma de denominação simbólica, dotada de extrema eficácia, não apenas pelo seu caráter de convencimento e sedução, mas pela busca natural das raízes ou do mito das origens.

Mas as exposições universais eram portadoras de outras mensagens, tais como a do progresso, idéia-mãe, norteadora do século XIX. 
Em certa medida, pode-se dizer que o homem do século XIX viveu sob a crença no progresso ilimitado, elemento central de uma visão do mundo na qual o futuro se antecipa como uma conquista assegurada. $O$ progresso material e os resultados dos avanços da ciência, de alguma maneira, fizeram com que "... o homem médio considerasse algo fantástico o crescimento infinito do poder humano sobre a natureza, ao mesmo tempo em que sua mente penetrava os segredos desta. (...) A 'déia do progresso é, pois, uma teoria que contém uma síntese do passado e uma previsão do futuro. Baseia-se numa interpretação da história, que considera o homem caminhando lentamente. (...) em uma direção definida e desejável e se infere que este progresso continuará indefinidamente" (Bury 1987).

Através dos olhos da burguesia, o progresso era desejável, o desenvolvimento da técnica produzia um mundo melhor e o futuro se apresentava como a concretização da sociedade do bemestar. Sem dúvida alguma, o progresso técnico fora obtido pelo pensamento racional. $O$ personagem-símbolo da racionalidade era também, sem sombra de questionamento, a burguesia triunfante que, com seu gênio criativo e sua racionalidade, fora capaz de "produzir" a moderna sociedade industrial. Desenvolvia-se, assim, uma particular forma de concepção da razão libertadora: a racionalidade fora capaz de romper as barreiras da ignorância e produzir a ciência. Por sua vez, o conhecimento científico, aplicado à técnica, concebera as máquinas e os novos e surpreendentes inventos.

Como evento de exibição de produtos e máquinas, a exposição reproduz, em escala maior que a fábrica, o processo de oculłação/demonstração próprio do fetichismo aludido por Marx. Se as mercadorias ocultam as relações sociais que as produziram, a exposição, por sua vez, opera no mesmo sentido, revelando o que interessa revelar e ocultando o que deve ser ocultado.

O corolário desta conjunção materializada do progresso, da técnica e da razão era a harmonia social. A ordem capitalista, produtora da sociedade do bem-estar, era justa e retribuía a cada um na medida de suas forças e, principalmente, do seu merecimento.

Neste sentido, as exposições buscavam seduzir os trabalhadores, demonstrando que eles eram os principais artífices daquela espiral de progresso que conduzia à sociedade do bem-estar.

Neste sentido, ganham força as palavras do historiador Robert Rydell (1984), atribuindo às exposições um caráter de "universo simbólico" porque pressupõem um conjunto de representações mentais que visam dar uma unicidade a um determinado projeto social. Ou seja, as exposições pretendem dar uma explicação global e totalizante sobre a realidade, conhecimento universal.

Símbolos dos novos tempos, as exposições foram ao mesmo tempo elementos de construção e de propaganda da sociedade industrial que se estruturava. Não é por acaso que o reclame e a propaganda surgem nesta época e se revelam de maneira especial nesses eventos, na maneira específica de apresentar os artigos, convencendo quanto ao seu uso, valor e necessidade.

Como refere Benjamin (1985), a publicidade é o artifício que permite ao sonho se impor à indústria e é ainda por ela que as pessoas se prendem ao sonho. 
Tais técnicas de propaganda e publicidade utilizam toda a persuasão e as "argúcias teológicas" da mercadoria (para usar a expressão de Marx, apud Benjamin| para se imporem, convencerem, seduzirem. Artifício de sedução social, a publicidade e a propaganda não são pura criação ou arbitrariedade imposta: elas se apoiam em tendencias latentes, em desejos manifestos, em inclinações não explícitas mas detectadas, e as manipulam, induzindo ao consumo, à aceitação, ao maravilhamento.

Mais importantes, contudo, eram as determinações implícitas nas imagens veiculadas pela propaganda: as pessoas eram levadas a admirar 0 poder criativo do homem, as potencialidades renovadoras da indústria, a engenhosidade dos empresários. As idéias de ordem, método e harmonia da sociedade burguesa conjugavam-se às noçōes de exemplaridade do sistema de fábrica e da inexorável marcha ascendente do progresso técnico.

Neste sentido, diz Kothe, a publicidade é sempre alegórica, prometendo na coisa concreta que oferece ao consumo, um outro valor que nela está contido. Cada elemento da propaganda tem um outro significado que não o seu significado literal.

Mas todas estas reflexões precisam ser historicizadas, assim como as imagens precisam ser coisificadas para que exerçam o seu poder. Tomemos 0 exemplo da Centennial, exposição norte-americana, realizada em 1876 para comemorar os cem anos da independência dos Estados Unidos.

No contexto americano, os Estados Unidos eram um caso à parte: eram anglo-saxões, europeus d'além-mar, que se posicionavam como uma projeção da raça e cultura européias. Em outras palavras, participavam, segundo o consenso mais ou menos generalizado da época, de um mesmo lastro comum formador de cultura, da civilização e dos avanços técnicos.

A superioridade européia em termos de ciência e tecnologia fora capaz de produzir máquinas que haviam transformado as condições de existência, contribuindo para a organização de uma sociedade em novos moldes e assentando a hegemonia global da Europa sobre o mundo (cf. Adas s.d.). Mais do que isło, estabelecera-se um padrão de avaliação internacional entre as sociedades européias, cultas e tecnificadas e as demais sociedades do mundo. Tais critérios de avaliação, que repousam em ciência, tecnologia e cultura, foram acompanhados da popularização de idéias mais ou menos científicas sobre a superioridade racial dos brancos, estabelecendo uma escala hierárquica entre povos, raças e regiōes. Este olhar europeu sobre o mundo forneceu uma concepção imaginária das sociedades, que legitimava a supremacia de uns sobre outros: de um lado, os brancos europeus, civilizados e detentores do saber científico e tecnológico, possuidores de uma refinada cultura; de outro, o resto da humanidade, não branca e/ou não européia, que se dispunha numa escala de selvageria, barbárie ou "primitiva inocência".

Naturalmente, a velha Europa se considerava superior mas distinguia o parceiro norte-americano das exposições universais como um rival de respeito.

Eugène Rimmel (1868: 321 ), contemporâneo das exposição parisiense de 1867, assim se pronunciou sobre a participação dos Estados Unidos neste certame: 


\begin{abstract}
"Nós diremos dos Estados Unidos o que dissemos da Rússia: eles estão longe de ocupar na exposição um espaço proporcional à extensão de seu território. Entretanto, os objetos que eles enviaram eram interessantes e caracterizam bem este povo saído de um imenso cadinho onde se fundiram os elementos europeus e que tomaram por divisa 'go ahead!' (...). Desde o início se viu que o objetivo principal dos americanos é substituir o braço que thes falta pela ajuda da máquina. As coisas mais simples e triviais se fazem a mecânica".
\end{abstract}

Destinado a alimentar o universo, como um verdadeiro "celeiro do mundo", dada a sua vasta extensão territorial, os Estados Unidos haviam também enveredado pelos caminhos da renovação técnica, do desenvolvimento industrial e da prospeç̧ão do petróleo mas ainda não haviam tido, nas exposições universais, um desempenho expressivo. Todavia, por ocasião do centenário de sua independência, os Estados Unidos iriam superar as expectativas. A idéia de realização das exposições, levada a efeito graças aos recursos privados dos cidadãos americanos, secundados pelo auxílio governamental - o governo federal, o Estado da Pensilvânia e a Municipalidade de Filadélfia - foi capaz de articular não apenas uma feira internacional, mas toda uma visão da América.

A Centennial atuou como um poderoso elemento de reafirmação de uma identidade coletiva nacional, articulando um conjunto de idéias, crenças, valores e mitos num todo articulado, socialmente desejável e intelectualmente compreensivel. Como refere Rydell (1984), a Exposição iniciava os visitantes numa "galáxia de símbolos que tornavam coerente um universo simbólico".

A América, pátria-mãe, berço acolhedor dos imigrantes, fora capaz de erguer-se como nação que surpreendia o mundo com o seu desenvolvimento tecnológico e a sua bem sucedida experiência de um governo democrático. Em suma, o mito do progresso, tão presente no imaginário do século XIX, encontrava a sua materialização inquestionável em terras americanas. Em tempo recorde, a jovem nação americana conseguira alçar-se ao nível tecnológico de outras potências. Nesta trajetória de desenvolvimento, fortalecia-se a autoimagem, consolidando-se noções tais como o "gênio inventivo" do povo americano ou o seu "senso prático", que, conjugados, eram capazes de presentear o mundo com novos inventos e descobertas, que contribuíam para tornar a vida mais fácil e consolidar a sociedade do bem-estar.

Elaborava-se, assim, um processo de construção de uma identidade coletiva, articulado em torno da idéia de Estado-nação. Os membros da comunidade eram levados a se auto-identificarem com um ethos americano, socialmente difundido, e a conceberem-se a si próprios como portadores daqueles valores determinantes do triunfo americano. Este processo envolvia uma relação do presente com o passado, bem como uma projeção para o futuro. Ou seja, o cidadão americano era o herdeiro das tradições gloriosas de um povo de desbravadores (os peregrinos, os conquistadores da terra, os vencedores dos índios, os heróis da independência, os construtores da democracial, numa saga a que, no presente, davam continuidade. Da mesma forma, dentro de tal visão evolutiva e ufanista, o futuro da América era previsível: a sua supremacia, a sua missão civilizatória, progressista e moralizadora eram os passos de um destino 
1. A propósito, consultar: The illustrated bistory of the Centennial Exbibition (1876); The illustrated catalogue of the Centennial Exbibition (1876); What we saw and bow we saw it (1876); Treasures of art, industry and manufacture in the American Centennial Exbibition (1877); Frank Leslie's illustrated bistorical register of the Centennial Exposition (1877); Official catalogue of the International Exbibition (1876); Illustrated bistorical register of the Centennial Exbibition ... (1879); Memorial of the International Exbibition (1877) inexorável. O povo americano era soberano e nada poderia afastá-lo do caminho natural que ele próprio construíra.

Neste sentido, a Exposição de Filadélfia de 1876 foi um dos momentos privilegiados da construção da nacionalidade e que obteve os resultados desejados. Como refere Rydell (1984), a exposição universal cumpriu uma função hegemônica, precisamente porque propagou as idéias e os valores dos líderes nacionais do mundo da política, das finanças, das corporações e da intelectualidade do país, oferecendo "estas idéias como a própria interpretação da realidade social e política".

As idéias de progresso tecnológico e afirmação da nacionalidade não podem, contudo, ser isoladas da noção de supremacia racial. Haviam sido os brancos, superiores cultural, moral e tecnicamente, os responsáveis pelo desenvolvimento econômico, pela construção da nação e pelo estabelecimento de uma sociedade democrática e civilizada. Para isso, não apenas contribuíam os avanços das leis evolucionistas (o que dava ao racismo um caráter científicol, como os próprios elementos da realidade histórica objetiva. Escravizar os negros e dominar os índios, arrebatando-lhes a terra, não era apenas um direito, mas um dever dos brancos, civilizados e superiores, de instaurarem uma ordem social mais "avançada". As maiores contribuições para o estabelecimento destas concepções racistas de entendimento da evolução humana, que concluía pela supremacia dos brancos sobre os demais, vieram da Smithsonian Institution, entidade de natureza científica que, já nesta época, se destinava a agregar um conjunto de instituições de investigação sobre os mais diferentes campos do conhecimento humano. Em particular, caberia referir que a América, consagrando o mito do self-made-man e da capacidade individual, viabilizava, no mundo dos negócios, a lei da sobrevivência e vitória dos mais aptos, presente na teoria evolucionista.

Caberia lembrar que os preparativos e a inauguração da Centennial se deram num momento de apogeu da luta vitoriosa dos brancos contra os indios e anos antes da Guerra Civil que pôs a nu a questão da escravidão nos Estados Unidos...

A todos estes fatores acrescentava-se ainda um elemento de conotação moral-religiosa: os valores do povo americano, profundamente religioso, que the davam o élan para o sucesso, que the outorgava o sentimento de autoconfiança e que se constituía no exemplo a ser seguido pelos demais povos. Neste contexto, a unidade nacional justapunha-se à idéia de que o destino dos americanos já se encontrava traçado em linhas triunfantes, como povo escolhido por Deus.

A Exposição de 1876 foi acompanhada da publicação de uma série de obras ilustrativas e explicativas daquilo que fora capaz a nação ao longo de cem anos de sua vida independente. O sentido laudatório é manifesto, e a América é apresentada como a terra da promissão, o maior exemplo de democracia já constituído na terra, a nação que, a partir de uma origem modesta e tímida, fora capaz de igualar-se, após um século, às maiores potências do mundo'. Não seria este um sinal de Deus de que a nação tinha o destino do sucesso?

A exaltação do espírito patriótico foi de grande oportunidade política para um ano de eleições nos Estados Unidos, tal como foi o de 1876 , 
desviando a atenção do público da bancarrota de empresas, de incidentes de corrupção financeira e política em Washington e de conflitos de operários, descontentes com as condições de trabalho (ct. 1876, a Centennial Exhibition).

A exaltação da figura da América como mãe-pátria, acolhedora dos povos e raças era uma constante. A capa de uma popular obra de divulgação da Centennial - Frank Leslie's illustrated historical register of the Centennial Exposition (1876) - trazia agrupados, no alto de um rochedo do qual se avistavam os prédios da Exposição, um grupo alegórico de cinco figuras. Duas delas - o índio norte-americano e o negro africano-islamizado - achavam-se ajoelhadas, mas com o rosto voltado para as figuras de pé. Destas, duas - uma estilo princesa oriental e a outra uma representação vulgarizada da Europa, com toga, coroa e ramo de oliveira - olhavam para a direção que apontava uma terceira figura. Esta, fisionomia ariana, adereço guerreiro nos pés, longo vestido modelado ao corpo por um rico cinto, deixava entrever a perna esquerda nua, avançada para a frente, e longos cabelos encimados por uma espécie de coifa ou capacele com penas (apud Rydell 1984: 12). Era a América, simbiose de raças e culturas? Talvez, mas o exotismo de um traje eclético não the desfigura o fenótipo da raça branca. Enfim, a América do Norte, ou os Estados Unidos, acolhia os demais - enquanto formação étnica, enquanto país hospedeiro de uma exposição universal -, mas o cerne do povo americano continuava a ser de extração anglo-saxã, branca e, portanto, superior.

Os versos de divulgação do evento contribuíam, por seu lado, para divulgar a conexão perfeita entre uma trajetória passada invejável e um futuro radioso:

"Come back across the bridge of time

And swear an oath that holds you fast

To make the future as sublime

As is the memory of the pay!"

(Fourth of July Memorial, apud Rydell 1984: 9)

Versos e canções não faltaram à Exposição de 1876, mobilizando os poetas da terra na celebração dos tempos novos e maravilhosos que a América vivia ${ }^{2}$.

A Exposição foi inaugurada em maio de 1876, revestindo-se de toda pompa e solenidade. Ao som da música de Wagner, que compôs um hino especialmente para a ocasião, o evento foi aberto com a presença do presidente Grant e do imperador do Brasil, D. Pedro Il, que, juntos, puseram em funcionamento a gigantesca máquina Corliss, produzida em Rhode island. Ocupando o centro do Machinery Hall, com um motor de $1.500 \mathrm{HP}$, mas podendo atingir a potência de $2.500 \mathrm{HP}$, pesando 700 toneladas, o engenho Corliss era a mais representativa prova da audácia norte-americana (cf. Union centrale des arts décoratifs 1983: 611. Colocando em movimento o engenho Corliss e seus enormes pistões, conectaram todas as máquinas do Machinery Hall, que principiaram a se mover. As crônicas da época teciam a respeito do colosso variadas considerações, sobre a capacidade aparentemente ilimitada do engenho humano.
2. Consultar, a propósito, "Song of the Centennial", de Joaquin Miller, considerado o "Byron do Oregon" apud The book of the fairs. 
3. Na verdade, D. Pedro II jamais teria exclamado ao experimentar o telefone: "Meu Deus, ele fala!".
É interessante verificar a atitude perante as máquinas. Animizadas, são comparadas aos seres humanos, dotadas não só de força mas de membros, coração, pulmões. No caso, o Corliss engine era saudado como "an athlete of stell and iron" (Prints and Photographs Division, Library of Congress apud Rydell 1884: 16).

Em contraposição, os operários ou trabalhadores são sempre representados em disciplina escolar, ordenadamente na fila para receber seu salário (cf. Union centrale des arts décoratifs 1983: 64), ou como uma esquadra ou brigada de homens valorosos, que, "armados" de vassouras, secundavam os demais, nas tarefas de limpeza da Exposição. O trabalhador mecanizava-se, tornava-se peça de uma engrenagem, um soldado do trabalho. Enquanto máquina adquiria, por inversão animística, as características do ser humano.

O colosso de Corllis foi, sem dúvida, uma das grandes atrações da Exposição, causando admiração a sua engenhosidade em proporcionar suficiente poder para operar todas as demais máquinas, dando uma visão impressionante do conjunto em movimento.

Mas a Centennial oferecia muito mais à multidão que acorreu ao evento. Que dizer do surpreendente invento de Alexander Graham Bell, que, como se disse, "fez falar o ferro"? Os testemunhos dos contemporâneos referiam o maravilhamento causado pelo novo aparelho:

"pequeno instrumento que se assemelhava a um bilboquê de vinte centímetros, munido de dois fios metálicos e que - dizia-se - reproduzia a voz humana a distâncias incalculáveis. Telefone: este era o nome do aparelho. Uma sociedade de cientistas, aos quais esta invenção parecia quase sobrenatural, fez logo experiências telefônicas sobre uma grande extensão: eles tomaram um dos fios da linha telefônica e em Nova York pode-se ouvir as palavras pronunciadas em Filadélfia, os menores sons estavam reproduzidos, tais como exclamações, risos, suspiros, respiração mesmo. (..) Nós nos perguntamos qual potência está fechada neste misterioso instrumento. A simplicidade mais absoluta é a sua divisa. E é esta simplicidade extraordinária que fez a mais grande honra ao gênio do Sr. Bell" (Dary George, 1883. In: Union centrale des arts décoratifs 1983: 60-11.

Invento maravilhoso, gerador até de um anedotário a seu respeito ${ }^{3}$, o telefone foi secundado por outros aparelhos, como a primeira máquina de costura, a primeira máquina de escrever prática e as mais recentes inovações norte-americanas para uso na agricultura. Em termos de novidades, a Centennial ainda apresentou um Pavilhão das Mulheres, onde puderam ser apreciados trabalhos executados por estas, que extrapolavam as costumeiras habilidades em costura, bordado ou pintura. As mulheres americanas surpreendiam os visitantes com inventos mecânicos para aplicação doméstica e industrial, terreno até então de domínio exclusivo do sexo masculino.

A América principiava a vender a imagem da emancipação feminina, das suas conquistas, potencialidades e da sua igualdade perante o sexo forte. As revistas e obras de divulgação apresentavam imagens de mulheres de semblante decidido, a discutir, deliberar. O Women's Pavillion fora concebido e pago pelas mulheres americanas, mas, contrastando com a imagem desejada de "nova mulher", registrava-se a lamentável constatação de 
que não havia mulheres no Comitê Executivo da Centennial, nem no seu Conselho de Finanças.

De uma forma geral, o conjunto dos produtos expostos era tão extenso que os jornais diziam ser impossível o visitante ver tudo num dia só. As charges ridicularizavam esta possibilidade, com a caricatura de um sujeito a correr, com um guia na mão, por entre as galerias, atropelando crianças, na sua desabalada carreira... (cf. Alwood 1977: 57).

A par deste aspecto de mostra do gênero criativo e do progresso técnico, a Exposição trazia ao público uma amostragem do exótico. Cabe referir que, ao longo do século XIX, a vulgarização da fotografia, aliada aos novos e instigantes estudos da Antropologia e da Etnografia, havia proporcionado a curiosidade por povos de diferentes tradições e costumes. Fotógrafos especializados viajavam até lugares distantes, trazendo fotos bem elaboradas de tipos característicos de cada cultura, verdadeiros estereótipos, e que eram colecionadas graças aos novos processos de reprodução técnica (cf. Stereotypes...). O povo americano entrou pela primeira vez em contato com produtos, gentes, estilos arquitetônicos e costumes de povos e países distantes. Muitos viam pela primeira vez um japonês ou um turco, revelando um verdadeiro espanto e mesmo repulsa. Neste sentido, o fascínio pelo exótico fortaleceu a crença na superioridade racial dos brancos. Mais do que isso, viabilizou-se uma espécie de imagem distorcida de índios que, apesar de ocuparem uma parte significativa na Exposição, não eram olhados com simpatia, e mesmo reforçou-se a idéia de que a solução correta seria a sua extinção. Os negros, no caso, eram vistos como exemplo da natureza humana num determinado estágio do seu desenvolvimento, mais precisamente a infância da humanidade...

Quanto aos asiáticos, a inferioridade racial destes povos consagrava, em tese, o direito e o dever dos civilizados brancos de ampliarem seus negócios sobre tais regiões do globo. Se os europeus dominavam a África dentro de um processo de expansão colonialista, a fatia de exploração que cabia aos americanos localizava-se no Oriente, mais especificamente no Japão, que cabia ser tutelado pelos Estados Unidos.

Não faltou também o aspecto feérico, de luzes, fogos de artifício e festas, temperado com muita pipoca e limonada, que fez acorrer aos eventos cidadãos americanos de todos os cantos do país.

Segundo sua auto-apreciação, os Estados Unidos não só haviam dado ao mundo uma demonstração do seu gênio, como a América comprovara ser uma nação de "primeiro mundo". Na verdade, transparecia mesmo a idéia de que, em muitos pontos, a jovem nação americana superara a velha Europa, pela sua produção em série e pelos engenhosos inventos que tornavam mais fácil e cômoda a vida cotidiana. $\bigcirc$ ufanismo exaltado levou mesmo à declaração do tipo que "a Inglaterra tinha mais dinheiro mas a América tinha mais cérebro!" (1876, a Centennial Exhibition: 22).

Todavia, a concepção do gênio americano tinha que competir com - génie français e, neste sentido, as críticas se fizeram sentir: se a América levava vantagem com o seu senso prático, a centelha da genialidade, do bom gosto e da arte permaneciam na França. A França ainda criticava os excessos e 
4. Os business men iam porque o país esperava que os seus homens mais proeminentes comparecessem; as moças casadoiras para ver se encontravam um charmoso estrangeiro; os rapazes em busca de uma herdeira; as elegantes para serem admiradas; o batedor de carteiras à cata de oportunidades (cf. Harper's Bazaar, 24 jun. 1876) ridículos do feminismo americano (cf. Needles, 1977: 31 ). Entretanto, as maiores críticas advieram do sistema de premiação, não distinguindo os mais simples dos mais bem representados. Na opinião francesa, uma medalha de bronze para todos era levar longe demais "O amor à uniformidade e a igualdade democrática" (Revue des deux mondes 1876: 799-800). A França resgatava, contudo, os pontos positivos, considerando os americanos "europeus do outro lado do oceano", como uma "nova Inglaterra além-mar", finalizando por concluir que, neste rumo ascensional, a França havia sido a sua mestra... (Revue des deux mondes 1876). Para selar este entrelaçamento, foram expostos - braço e a tocha da futura Estátua da Liberdade, encomendada a Bartholdi, com que o governo francês pretendia presentear os Estados Unidos, rememorando o auxílio prestado por ocasião dos conflitos da Independência americana. Que melhor imagem da vocação libertária daquele país, que se configurava como a nova Terra da Promissão?

Por outro lado, as revistas da época, com suas caricaturas e quadros cômicos, ironizavam o atropelo e o deslumbramento com que os "matutos" do interior acorriam à Exposição (cf. Harper's Bazaar 15 jul. 1876), ou mesmo os motivos pelos quais a população acorria em massa ao evento (cf. Harper's Bazaar 24 jun. 1876) 4 .

Deve ser ressaltado que, no caso da sátira, faz-se a leitura não-oficial das motivações da Exposição, ressaltando o cotidiano do evento e os interesses particulares de cada um, que nada tinham a ver com a visão propriamente política de realização da Centennial. O que flui da leitura das piadas contemporâneas ao evento é o aspecto lúdico e bizarro da Exposição, além do fato de a mesma não ser só mostruário de objetos, mas vitrine de pessoas, onde os indivíduos assumiam a conotação de mercadorias. Retoma-se, aqui, a mercantilização da vida e a aparência dos fenômenos que escondem a essência dos processos vividos, já anteriormente aludida.

Para a tropical monarquia dos Bragança, a Exposição foi muito além da expectativa dos povos europeus. Enfim, a modernidade atravessava $\circ$ oceano e comprovava-se ser possível a aventura do progresso em terras americanas. Os Estados Unidos, que também haviam sido colônias d'além-mar, eram o exemplo vivo de que era possível acompanhar o trem da história.

A opinião entusiamada da elite brasileira transparece nos relatórios da participação brasileira na Centennial ou da exposição nacional de 1875 , preparatória para a internacional de 1876. O Brasil não deveria temer se expor à crítica internacional, seguindo o exemplo dos Estados Unidos, que ousara disputar com a Europa (cf. Exposição Nacional de 1875, 1876: 5). Se, por um lado, a Exposição lavrava um tento nos rumos do progresso industrial, por outro, era mais um degrau na escala da ciência, causando um "efeito mágico sobre o espírito ávido de saber" (Exposição Nacional de 1875, 1876: 21). A América dava ao mundo o melhor exemplo de amor ao trabalho, espírito de associação, emprego útil do tempo e alto espírito de iniciativa (cf. COMISSÃO BRASILEIRA...).

Primeira nação a aceitar o convite do governo norte-americano, o Brasil, como de praxe, realizou exposiçōes provinciais preparatórias da exposição nacional, quando seriam selecionados os produtos a serem enviados 
para a Filadélfia. Nestes eventos, destacaram-se três províncias: as do Rio de Janeiro, São Paulo e Rio Grande do Sul.

Sólidos interesses uniam os dois países, tendo em vista a comercialização do café e a Exposição era uma ótima oportunidade para tornar-se melhor conhecido do conjunto da população americana, que já consumia cerca de metade da produção brasileira.

No evento da Filadélfia, em 1876, o Brasil empenhou-se em levar uma amostragem a mais completa possivel das potencialidades do país. $\bigcirc$ que ressaltava, contudo, eram as potencialidades de suas riquezas naturais: café, madeiras, minérios, plantas exóticas. Por um lado, o país era identificado como a maior nação da América do Sul, tal como os Estados Unidos eram a maior nação da América do Norte. A comparação em si tinha mais validade simbólica do que efetiva, se fossem comparados os padrões de desenvolvimento capitalista das duas potências...

Para a edificação de seu pavilhão, mais uma vez o Brasil optara por um estilo mourisco, sem muito a ver com as tradições arquitetônicas lusas, mas de grande efeito pelas cores variadas e brithantes e pela ornamentação exótica, que incluía flores artificiais, penas de pássaros, borboletas e insetos, ou mesmo amostras de algodão que se dispunham a recobrir as paredes (cf. The illustrated history ...., 1876: 421 e Lippincott's magazine ..., 1876: 6541.

Mas, realmente, a grande figura do evento foi dada pela simpatia pessoal, a simplicidade de maneiras, a educação e a profunda curiosidade intelectual por toda a Exposição, demonstrada pelo imperador D. Pedro II. Fontes americanas e francesas não cessaram de elogiá-lo, ressaltando a distinção do casal imperial, a sua cultura, contrastando com a sua simplicidade de maneiras e o minucioso interesse com que examinou os objetos expostos.

Todavia, a opinião favorável à figura do imperador e às potencialidades do país em geral, traduzidas numa copiosa e diversificada amostragem, não eram acompanhadas de um movimento de simpafia para com os brasileiros em geral. É extremamente significativa a charge apresentada pelo Harper's Bazaar, na qual D. Pedro aparecia ladeado por brasileiros com cabeça de animal (burros e gansos), acompanhada de uma legenda nitidamente depreciativa a respeito dos compatriotas do imperador nos Estados Unidos, que o cercavam a dizer asneiras... ${ }^{\text {. }}$.

Qual, pois, foi o saldo da participação brasileira no evento? Não é possivel generalizar e dizer que os relatórios oficiais traduzem somente uma visão ufanista. Há uma relativa percepção da defasagem entre as condições brasileiras e as das grandes potências, às quais se acrescentava o desejo de ver o país ingressar nos rumos da modernidade:

"Não nos iludamos: o que mereceu aplausos na Exposição foi quase tudo obra da natureza; o trabalho do homem entrou ai com pequena parcela, mas, felizmente, tanto quanto bastou para demonstrar que não somos indignos das riquezas que possuimos. O melhor exemplo que podemos imitar para alcançar a prosperidade temo-lo neste mesmo país que tão bem nos acolheu e julgou-nos, nesse povo despido de preconceitos, ativo, simples, que eliminou as rudezas do trabalho e tornou-o fácil e agradável, com aplicaçāo das máquinas em todos os misteres, permitindo desle
5. A legenda, apresen tada na edição do Haper's Bazaar, de 27 de maio de 1876 , era a seguinte: "Do give the good man a chance! $D$. Pedro and the Braysilly-uns' of the United States". A blague do vocábulo brazilians (brasileiros) é feita com as palavras inglesas bray (zurrar) e silly (tolo). 
modo ao homem o exercício pleno de sua inteligência ou da força que o nobilita, distinguindo-o do bruto. Todo trabalho é considerado no mesmo pé de igualdade e é por amor dele, e dele tão somente, que se alcança a consideração social. Trabalhase ali por obrigação e devoção, trabalham ricos e pobres do mesmo modo, não exclusivamente por amor de recompensa, mas também com os olhos fitos no céu" (Comissão Brasileira, 1878: 50).

Em suma, frente à busca de uma identidade nacional e um determinado perfil para o país, a elite intelectualizada voltava-se para os novos valores burgueses do amor ao trabalho e do esforço pessoal, ao qual se conjugava a crença nas possibilidades redentoras da máquina. Num país que, a partir da segunda metade do século XIX, lentamente transitava do escravismo para $\circ$ capitalismo, tornava-se premente consolidar uma pontuação valorativa do trabalho. O trabalho braçal, coisa de negro e de escravo, e, como tal, negativamente privilegiado, passava a ser reordenado segundo uma nova moral burguesa. $O$ trabalho era digno, tinha em si um valor positivo e era uma prática louvável.

Na busca de si mesma, a nação reorientava seus valores e crenças a partir de uma nova ética, que não apenas punha o selo da modernidade como também legitimava a introdução da mão-de-obra livre, qualificando-a e ressaltando as suas possibilidades para o desenvolvimento do país.

O relatório enfatizava que não era possivel continuar a nação iludida com as suas potencialidades naturais. A solução, que indicava o caminho do país desejado era a do trabalho e da máquina.

Trabalho livre e tecnologia, eis os elementos-chave do caminho do progresso, que o Brasil deveria trilhar para atingir o status do moderno.

Todavia, para os Estados Unidos, a grande questão dava-se em torno do café, identificando-se que a visita do imperador e o seu empenho na participação brasileira na Centennial dera novo impulso aos negócios entre os dois países, "... o que foi bom, tendo em vista a competição com a GrãBretanha e a França no tocante aos bens manufaturados de todas as classes comprados pelo Brasil a estas nações" (Treasures of art ..., 1877).

Já se afirmou que as imagens são simbólicas e exprimem uma metaforização do social, reconstruindo o real através de um universo paralelo de sinais. Através das imagens da nação, do progresso e da tecnologia veiculadas pelas exposições universais do século XIX e, particularmente, pela exposição norte-americana de 1876, estamos em face do que se poderia chamar de "desterritorialização do objeto" e oscilação de sentido.

No mundo conduzido pelo espetáculo da modernidade, a vulgarização das imagens uniformizava o padrão da mensagem explícita - o progresso, o avanço técnico, o poder da nação, o britho da cultura -, mas respondia a realidades distintas. Todavia, enquanto representação, o imaginário é capaz de associar idéias e imagens não vizinhas e produzir um significado de similitudes, com um deslocamento de sentido. Em condições de realização capitalista, Brasil e Estados Unidos se colocavam frente a um jogo de espelhos, respondendo um ao outro.

Os Estados Unidos projetando a sua identidade e generalizando a utopia do sonho americano, exemplo concreto do sucesso capitalista do lado 
de cá do oceano. A monarquia brasileira elaborando uma auto-imagem que tinha o seu modelo no exterior e que, enquanto realização, estaria condicionada pelo seu caráter perverso, marcado pela escravidão, pelo latifúndio, pela vinculação com o mercado internacional.

\section{BIBLIOGRAFIA}

ADAS, Michael. Machines as the measure of men. Science, technology and ideologies of western dominance. Ithaca/London: Cornell University Press, s.d.

ALWOOD, John. The great exbibitions. London: Studio Vista, 1977.

BENJAMIN, Walter. Paris, Capitale du XIXe siècle. In: KOTHE, Flávio, org. Walter Benjamin. São Paulo: Ática, 1985. p. 30-122. [Grandes cientistas sociais, 52].

BENJAMIN, Walter. A obra de arte na era de sua reprodutibilidade técnica. In: BENJAMIN, Walter. Obras escolbidas: magia e técnica, arte e política. São Paulo: Brasiliense, 1986.

BOURDIEU, Pierre. Ce que parler veut dire. Paris: Fayard, 1982.

BURY, John Bagnell. Idea of progress: an inquiry into its origin and growth. New York: Dover, 1987.

CASTORIADIS, Cornelius. A instituição imaginária da sociedade. 3.ed. São Paulo: Paz e Terra, 1991. [Rumos da cultura moderna, 52].

CHARTIER, Roger. Le passé composé. Traverses, n.40 (théatres de la mémoire), p. 6-17, abr. 1987.

COMISSÃO BRASILEIRA. Exposição centenária da Filadélfia, Estados Unidos, em 1876. Rio de Janeiro, Relatório.

DUBOIS, Claude. L'imaginaire et la prospective au XVIe siècle: formalisme scientifique et réalisme imaginaire. Cabiers de l'imaginaire, n.1, 1988.

DURAND, Gilbert. Les structures antbropologiques de l'imaginaire. Paris: Bordas, 1984.

DURAND, Yves. L'exploration de l'imaginaire. Paris: L’Espace Bleu, 1988.

EXPOSIÇÃO Nacional de 1875. Notas e observações de Rozendo Moniz Barreto. Rio de Janeiro: Typ. Nacional, 1876.

FRANK Leslie's illustrated historical register of the Centennial Exposition, 1876. New York: F. Leslie's, 1877.

ILLUSTRATED historical register of the Centennial Exhibition Philadedelphia, 1876 and of the Exposition universelle de Paris, 1878. New York: American News Co., 1879.

LIPPINCOTT'S magazine of popular literature and science, v.18, 1876. 
MEMORIAL of the International Exhibition. Hartford: L. Stebbins, 1877.

HAMON, Pierre. Images à lire et à voire. In: MICHAUD, Stéphane; MOLLIER, Jean-Yves; SAVY, Nicole, dir. Usages de l'image au XIXe siècle. Paris: Créaphis, 1992. p.235-248.

HARPER'S BAZAAR, 24 jun. 1876

HARPER'S BAZAAR, 15 jul. 1876.

MARIN, Louis. Des pouvoirs de l'image. Paris: Seuil, 1992.

MICHAUD, Stéphane. Introduction. In: MICHAUD, Stéphane; MOLLIER, Jean-Yves; SAVY, Nicole, dir. Usages de l'image au XIXe siècle. Paris: Créaphis, 1992.

NEEDLES, Samuel H. A French view of the grand international exposition of 1876. Philadelphia: Claxton, Romsen and Haffélfinger, 1977.

OFFICIAL catalogue of the International Exhibition, 1876. Philadelphia: John R. Nagle and Co., 1876.

POST, Robert, ed. 1876: a centennial Exbibition. Washington D.C.: The National Museum of History and Technology, Smithsonian Institution, s.d.

REBÉRIOUX, Madeleine. Approches de l'histoire des expositions universelles à Paris du Second Empire à 1900. Bulletin du Centre d'histoire économique et sociale de la région lyonnaise, n.1, p. $1-17,1979$.

L'iconographie des histoires de la Révolution française au XIXe siècle: esquisse d'une problématique. In: MICHAUD, Stéphane; MOLLIER, Jean-Yves; SAVY, Nicole, dir. Usages de l'image au XIXe siècle. Paris: Créaphis, 1992.

REVUE DES DEUX MONDES, 15 out. 1876

RIMMEL, Eugène. Souvenirs de l'exposition universelle. Paris: E. Dentu, 1868.

RYDELL, Robert W. All the world's a fair: vision of empire at American international expositions, 1876-1916. Chicago/London: University of Chicago, 1984.

STEREOTYPES, a book of postcards: ethnics photographs of the nineteenth century, s.l. s.d.

TREASURES of art, industry and manufacture in the American Centennial Exhibition at Philadelphia, 1876. Buffalo, New York: Cosack and Co., 1877.

THE BOOK of the fairs. Washington: Smithsonian Institute. s.d.

THE ILLUSTRATED catalogue of the Centennial Exhibition. Philadelphia / New York: John Filmer, 1876. 
THE ILLUSTRATED history of the Centennial Exhibition. New York: John Filmer, 1876.

THE ILLUSTRATED history of the Centennial Exhibition. Philadelphia: National Publishing Co., 1876.

UNION CENTRALE DES ARTS DECORATIFS. Le livre des expositions universelles, 1851-1989. Paris: Editions des Arts Décoratifs/Herscher, 1983.

WHAT we saw and how we saw it. Philadelphia: S.T. Sonder, 1876. 
se investigar não apenas a natureza dessa mudança, mas sobretudo os mecanismos subjacentes que a determinaram, sendo aqui apresentados os seus resultados.

UNITERMOS: Cemitérios. Imaginário funerário. Rio de Janeiro oitocentista. Emergência da sociedade burguesa.

Anais do Museu Paulista: N.Ser. v. 2, 1994.

From bats and death's heads to crosses and books: the representation of death at 19th-century cemeteries in Rio de Janeiro

Tania Andrade Lima

Following the assumption that spaces alloted to the dead specularly reflect the world of the living, both of them under the rules of the same logics, the A. considers the cemeteries as the locus of the symbolic reproduction of social universe and, henceforth, as a favoured domain to infer the processes through which bourgeois values are introduced and strengthened in 19th-century Rio de aneiro's society. Within the framework of the disruption of the proslavery state, in the 1880s, as well as of the emergence of a growing capitalistic republic, she detects eventual changes of the collective imaginaire concerning death, at Rio's cemeteries. The results of her fieldwork are discussed, related not only to the nature of changes, but also to the underlying mechanisms that provoked them.

UNITERMS: Cemeteries. Funerary imaginaire. 19th-century Rio de Janeiro. Emergence of bourgeois society. Anais do Museu Paulista: N.Ser. v. 2, 1994.

Imagens da nação, do progresso, da tecnologia: a Exposição Universal de Filadélfia de 1876

Sandra Jatahy Pesavento

Após considerar premissas sobre as imagens como representações sociais e sobre as Exposições Universais como um teatro privilegiado para a exibição daquela hermenêutica do real engendrada pela transformação capitalista do mundo e pelo ideário burguês, incluindo ainda a dimensão utópica da época, a A. brevemente caracteriza a Exposição do Centenário Ida Independência Americanal, na Filadélfia, 1876. Comenta a presença de um pavilhão brasileiro e os ecos da visita do Imperador D.Pedro II. Enfim, confronta sentidos divergentes, quer se trate da auto-imagem de sucesso do "sonho americano", quer das contradições de uma identidade brasileira que tenta incorporar a nova ética do trabalho livre mecanizado, numa sociedade escravocrata e vinculada ao mercado internacional.

UNITERMOS: Exposições universais. Exposição do Centenário (Filadélfia, 1876). Exposição universal e identidade brasileira.

Anais do Museu Paulista: N.Ser. v.2, 1994.

Images of the nation, progress and technology: the World Exposition of Philadelphia 1876

Sandra Jatahy Pesavento

After laying down her assumptions on images as social representations and on World's Fairs as a privileged scene for displaying the hermeneutics of reality engendered by the capitalist transformation of the world, along with the bourgeois ideology and the utopian longings of the epoch, the A. briefly describes the main features of Philadelphia's Centennial Exposition in 1876. She then comments the presence of a Brazilian pavillion and the visit of Brazil's Emperor, D. Pedro Il. She finally traces a parallel between divergent meanings of the Exhibition as related to the successful autoimage of the "American dream" in opposition to the contradictions of Brazilian identity, vainly endeavouring to incorporate the new ethics of free mechanical labour in a dependent proslavery sociely.

UNITERMS: World Expositions. Centennial Exposition (Philadelphia, 1876). World Expositions and Brazilian identity. Anais do Museu Paulista: N.Ser. v.2, 1994 